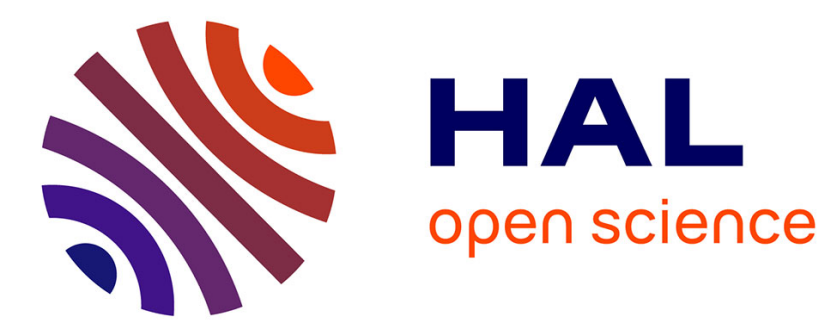

\title{
Highly Coupled and Low Frequency Vibrational Energy Harvester Using Lithium Niobate on Silicon
}

Giacomo Clementi, Merieme Ouhabaz, Samuel Margueron, Miguel Angel

Suarez, Florent Bassignot, Ludovic Gauthier-Manuel, Djaffar Belharet,

Bernard Dulmet, Ausrine Bartasyte

\section{To cite this version:}

Giacomo Clementi, Merieme Ouhabaz, Samuel Margueron, Miguel Angel Suarez, Florent Bassignot, et al.. Highly Coupled and Low Frequency Vibrational Energy Harvester Using Lithium Niobate on Silicon. Applied Physics Letters, 2021, 119, pp.013904 (12). hal-03360025

\section{HAL Id: hal-03360025 \\ https://hal.science/hal-03360025}

Submitted on 30 Sep 2021

HAL is a multi-disciplinary open access archive for the deposit and dissemination of scientific research documents, whether they are published or not. The documents may come from teaching and research institutions in France or abroad, or from public or private research centers.
L'archive ouverte pluridisciplinaire HAL, est destinée au dépôt et à la diffusion de documents scientifiques de niveau recherche, publiés ou non, émanant des établissements d'enseignement et de recherche français ou étrangers, des laboratoires publics ou privés. 


\title{
Highly Coupled and Low Frequency Vibrational Energy Harvester Using Lithium Niobate on Silicon
}

\author{
Giacomo Clementi ${ }^{1 *}$, Merieme Ouhabaz ${ }^{1}$, Samuel Margueron ${ }^{1}$, Miguel Angel Suarez ${ }^{1}$, Florent \\ Bassignot $^{2}$, Ludovic Gauthier-Manuel ${ }^{1}$, Djaffar Belharet ${ }^{1}$, Bernard Dulmet $^{1}$ and Ausrine Bartasyte ${ }^{1}$ \\ ${ }^{1}$ FEMTO-ST Institute, University of Bourgogne Franche-Comté, CNRS (UMR 6174), ENSMM, 26 \\ rue de l'Epitaphe, 25030 Besançon, France \\ ${ }^{2}$ FEMTO Engineering, 15B Avenue des Montboucons, 25030 Besançon, France \\ ${ }^{*}$ Corresponding author: giacomo.clementi@femto-st.fr
}

\begin{abstract}
LiNbO}_{3}$ has been little studied for the piezoelectric energy harvesting applications. Although, it is a cheap piezoelectric material without lead and toxic elements, and it beneficiates of technological maturity in single crystal fabrication for optical and acoustic applications. In this letter, we propose to investigate a (YXlt) $/ 128^{\circ} / 90^{\circ} \mathrm{LiNbO}_{3}$ cut as it offers a transverse piezoelectric coupling of $\mathrm{k}_{23}=0.49$ which is comparable to that of commonly used PZT ceramics. A flexible beam of $65 \mathrm{~mm}$ length and tip mass made of $\mathrm{LiNbO}_{3}$ thick film bonded on silicon was studied under $0.1 \mathrm{~g}$ sinusoidal acceleration. The beam presented an open-circuit resonance frequency of $105.9 \mathrm{~Hz}$ and a displacement up to $1.5 \mathrm{~mm}$. In the frame of single degree of freedom lumped model with rectifying bridge, the electromechanical coupling of the device $\left(\mathrm{k}_{\mathrm{m}}{ }^{2}\right)$, the figure of merit $k_{m}{ }^{2} Q$ and the normalized average power density were compared to both $\mathrm{Pb}$-based and $\mathrm{Pb}$-free current devices. The generated power density by our device was $965 \mu \mathrm{W} / \mathrm{cm}^{2} / \mathrm{g}^{2}$, which is among the highest reported values compared to both $\mathrm{Pb}$ - and $\mathrm{Pb}$-free vibrational harvesting devices.
\end{abstract}

Keywords: $\mathrm{LiNbO}_{3}$, lead-free, piezoelectric material, vibrational energy harvesting

Energy harvesting and ultra-low power electronic are urgently needed for the implementation of selfpowered, battery- and maintenance-free sensors [1]. The integrated solutions with energy harvester are highly demanded in the market of the Internet of Things, health monitoring and more generally 4.0 industry [2]. Vibrational energy harvesting is frequently considered as an alternative solution to photovoltaics for this purpose. The specifications of vibrational sources available in vehicles or industrial environments are low acceleration levels $\left(<1 \mathrm{~g}=9.81 \mathrm{~m} / \mathrm{s}^{2}\right)$ and frequencies $(<500 \mathrm{~Hz}) . \mathrm{Pb}-$ containing piezoelectric materials such as $\mathrm{PbZr}_{1-\mathrm{x}} \mathrm{Ti}_{\mathrm{x}} \mathrm{O}_{3}(\mathrm{PZT})$ ceramics are usually considered as the best performing electro-mechanical transducers. They are implemented in form bulk ceramic, fibers [3] or thin films. Recently, it has been shown that the thickness of the piezoelectric layer can be optimized [4], where a $57 \mu \mathrm{m}$ PZT ceramic film was fabricated in unimorph configuration by means of phosphor- 
bronze bonding and mechanical lapping, achieving $321 \mu \mathrm{W}$ at $100.8 \mathrm{~Hz}$ for high acceleration applications (up to $3 \mathrm{~g}$ ). Kuo et al [5] have fabricated by aerosol deposition thick PZT films $(15 \mu \mathrm{m})$ in bimorph configuration on stainless steel, obtaining $423 \mu \mathrm{W}$ at $143.5 \mathrm{~Hz}$ for $1.5 \mathrm{~g}$ acceleration level. In other works, sputtered films were exploited [6] in form of bimorph harvesters on flexible Ni foils, obtaining higher power densities, $60 \mu \mathrm{W}$ at $70 \mathrm{~Hz}(0.5 \mathrm{~g})$. Relaxor ferroelectrics in form of single crystals such as $\mathrm{Pb}\left[\mathrm{Mg}_{1 / 3} \mathrm{Nb}_{2 / 3}\right] \mathrm{O}_{3}-\mathrm{PbTiO}_{3}(\mathrm{PMN}-\mathrm{PT})$ or $\mathrm{Pb}\left[\mathrm{Zn}_{1 / 3} \mathrm{Nb}_{2 / 3}\right] \mathrm{O}_{3}-\mathrm{PbTiO}_{3}(\mathrm{PZN}-\mathrm{PT})$ are also considered for harvesting applications, although they are quite brittle and expensive. A comparison of PZT, PMN-PT and PZN-PT was presented [7], and the experimental results indicated that relaxor ferroelectrics can significantly outperform PZT ceramics energy harvesters, attaining $0.43 \mathrm{~mW}$ at 37.5 $\mathrm{Hz}$ at $0.3 \mathrm{~g}$. Despite the outstanding results, these devices are still exploiting $\mathrm{Pb}$-based materials that represent an environmental issue, and do not respect REACH and RoHS regulation in EU.

On the other hand, $\mathrm{Pb}$-free materials have been also investigated for applications at low acceleration and low excitation frequency. One of the highest performances were obtained for AlN devices [8] capable of working at $58 \mathrm{~Hz}$ and generating $63 \mu \mathrm{W}$ at $0.7 \mathrm{~g}$. Ferroelectric polymer PVDF has been also considered for low frequency applications $(30.7 \mathrm{~Hz}$ ) but has a limited power output ( $8 \mu \mathrm{W}$ at $0.5 \mathrm{~g}$ ) [9]. The potassium and sodium niobate $(\mathrm{KNN})$ family have shown promising results especially for MEMS applications. For instance, it was possible to attain a resonance frequency of $126 \mathrm{~Hz}$ and $7.7 \mu \mathrm{W}$ at 1.02 $\mathrm{g}$ by using KNN films on metal foils, deposited by hydrothermal method [10].

Among the $\mathrm{Pb}$-free materials, very well-known lithium niobate $\left(\mathrm{LiNbO}_{3}\right)$ has drawn little attention as an electro-mechanical transducer in the literature [11], due to its low piezoelectric coefficients. $\mathrm{LiNbO}_{3}$ is a ferroelectric material with extremely high Curie temperature $\left(1100^{\circ} \mathrm{C}\right)$ that belongs to $\mathrm{R} 3 \mathrm{c}$ space group at room temperature and that is commercially available at low price in form of high-quality poled single crystal wafers with diameter up to 6 inches $(<25 \$ /$ wafer $) . \mathrm{LiNbO}_{3}$ elastic, piezoelectric and dielectric constants have been extensively studied [12] and its electro-mechanical coupling can be optimized as a function of crystal orientation [13]. Following IEEE standard on piezoelectricity [14], we can define the electro-mechanical coupling of $\mathrm{LiNbO}_{3}$ (YXlt) $/ 128^{\circ} / 90^{\circ}$ crystal cut as $\mathrm{k}_{23}=$ $\sqrt{\frac{\mathrm{d}_{23}{ }^{2}}{s_{33}{ }^{E} \varepsilon_{22}{ }^{T}}}=0.49$, taking the rotated piezoelectric coefficient $\mathrm{d}_{23}=-27 \mathrm{pC} / \mathrm{N}$, dielectric constant $\varepsilon_{22}{ }^{T} / \varepsilon_{0}=50.5$, and elastic compliance $s_{33}{ }^{E}=6.91 \mathrm{pm}^{2} / \mathrm{N}$. Therefore, the chosen orientation of $\mathrm{LiNbO}_{3}$ has an expected stress-driven figure of merit $\left(\mathrm{FoM}^{-1}=\frac{\mathrm{d}_{23}{ }^{2}}{\varepsilon_{22}{ }^{T}}\right)$ of $0.61 \mathrm{MJ} / \mathrm{cm}^{3}$. This value is comparable with commercially available ceramics (PZT-5A, PZT-5H) and superior than other Pb-free materials (AlN, KNN, PVDF), where a detailed comparison of piezoelectric properties figure of merit is given in a recent work [15].

The implementation of $\mathrm{LiNbO}_{3}$ in form of bulk crystals for purpose of energy harvesting, shows too low capacitance and results challenging for electronic interfacing and impedance matching [16]. Instead, the 
thick films obtained by wafer on wafer technology [17], highly investigated in the field of acoustics and optics [18], allowed to address the capacitance issues and to show high vibrational energy harvesting efficiency at high acceleration $(3 \mathrm{~g})$ and frequencies in the $\mathrm{kHz}$ range [15]. In this paper, we have addressed the issue of the $\mathrm{LiNbO}_{3}$-based vibrational harvester compatibility with vibrations available in the environment by lowering down the resonance frequency to $\sim 105.9 \mathrm{~Hz}$ of $\mathrm{LiNbO}_{3} / \mathrm{Si}$ beams, in order to attain high power densities under very low acceleration levels $(0.1 \mathrm{~g})$. The harvester was described by using the single degree of freedom lumped model and has been studied under resistive load near the resonance frequency.

The cantilevered beams were fabricated in the clean room by first bonding two substrates (Fig. 1a): a $500 \mu \mathrm{m}$ thick (100) Si wafer and a $350 \mu \mathrm{m}$ thick single crystal (YXlt) $/ 128^{\circ} / 90^{\circ} \mathrm{LiNbO}_{3}$ wafer. For this purpose, a $30 \mathrm{~nm} \mathrm{Cr}$ and $170 \mathrm{~nm}$ Au layers were sputtered on the polished surface of both wafers. The wafers were bonded by vacuum thermocompression at room temperature. The bonding interface quality was investigated by ultrasonic non-destructive testing in transmission [17]. The Fig. 1b presents in false colors the impedance matching in bonded wafers. The good quality of bonding corresponds to red color, while blue and green colors are related to bonding defects like air gap, roughness or dust particles at the interface. The thickness of $\mathrm{LiNbO}_{3}$ was thinned down to approximately $30 \mu \mathrm{m}$ by mechanical lapping and micro-polishing. The typical Total Thickness Variation (TTV) achieved was $2 \mu \mathrm{m}$. The top electrodes ( $200 \mathrm{~nm}$ thick $\mathrm{Cr} / \mathrm{Au}$ ), deposited by electron-beam evaporation, were patterned by $\mathrm{UV}$ lithography and lift-off. The top electrode was covering $2 / 3$ surface of the total final length. The devices were subsequently diced in rectangular beams of $65 \mathrm{~mm}$ length and $10 \mathrm{~mm}$ wide. The Si backside was protected with tape in order to leave $10 \mathrm{~mm}$ on each side. The unprotected beam was etched at the central part by deep reactive ion etching (DRIE) until thickness of $360 \mu \mathrm{m}$. The good bonding quality after dicing was confirmed by imaging the heterostructure cross-section by a scanning electron microscope (SEM-Apreo S, Fig. 1c). The final device was then clamped in between rigid aluminum bars. The top electrode was wire-bonded to a PCB while the bottom electrode was connected to the other branch of the circuit contacting the Au-Au layer using silver paste. The photo of the sample wire-bonded to the clamping system is given in the inset of Fig. $1 \mathrm{~d}$.

The setup for the vibrational measurements consisted of a shaker, providing the sinusoidal excitation for the vibrational tests, coupled with an accelerometer mounted at the base of the clamping system to monitor the magnitude of the input force (Fig. 1d). Meanwhile, the displacement of the tip was tracked by a laser interferometer with $50 \mu \mathrm{m}$ resolution, giving a relative error of $2.5 \%$ for the measurements at resonance. Typically, the acceleration magnitude range used was $0.1 \pm 0.02 \mathrm{~g}$. The voltage levels were measured both with an oscilloscope (LeCroy LT344) using a $10 \mathrm{M} \Omega$ attenuation probe, or with a Keithley 6517B electrometer after diode rectification, and connected to a National Instruments Labview interface. 
The voltage response at open-circuit frequency $(105.9 \mathrm{~Hz})$, measured experimentally, where the harvester showed a voltage peak of $15.1 \mathrm{~V}$ (RMS). This result is compared to the response simulated with Finite-Element modelling (using COMSOL® software), which shows the linear behavior of the harvester reaching a voltage peak of $16 \mathrm{~V}$ (RMS) (Fig. 2a). The modeled peak presents a shift towards higher frequencies $(106.2 \mathrm{~Hz})$ with respect to the experimental one. The experimental data is in good agreement with the simulations, even though the voltage levels seemed to be slightly overestimated (by 0.9 volt). This deviation was modeled in some recent works [19], and it was related to softening of the silicon substrate, which appeared whenever the restoring force decreases with the displacement. Nevertheless, the bending mode of the beam was attained in the expected frequency range and at low acceleration levels, which are compatible with environmental vibrations $(<1 \mathrm{~g})$.

The electrical impedance of our device was investigated by using a network analyzer (Keysight E5061B) and by applying a Butterworth Van Dyke (BVD) equivalent model. The impedance was measured from $10 \mathrm{~Hz}$ to $100 \mathrm{kHz}$ at room temperature. The samples showed very small dielectric losses $(\tan \delta=0.24$ $\%$ ) and a clamped capacitance of $C_{0}=5.8 \mathrm{nF}$ at $2 \mathrm{kHz}$ measured away from resonance, confirming the good quality of the single crystal. The electrical resonance was observed at $104.53 \mathrm{~Hz}$, and it is presented along with the BVD fitted parameters in Fig. $2 b$.

To investigate $\mathrm{LiNbO}_{3}$ thick film on silicon as a competitive alternative for highly coupled energy harvesters, our results were analyzed through the widely used single degree of freedom model. The harvester operating close to its resonance frequency $\left(\omega_{0}\right)$ can be approximated as an effective spring $(K)$, damper $(C)$ and mass $(M)$ system (Fig. 3a). The dynamic equations connecting the electrical and mechanical sub-systems are:

$$
\left\{\begin{array}{c}
M \ddot{y}=M \ddot{x}+C \dot{x}+K x+\alpha V \\
I=\alpha \dot{x}-C_{0} \dot{V}
\end{array}\right.
$$

where the term $M \ddot{y}$ represents the external force acting on the harvester, while $\dot{x}$ is the relative displacement of the mass. The piezoelectric element with clamped capacitance, $C_{0}$, converts the kinetic energy given by the velocity, $\dot{x}$, in electrical current, $I$, by means of the force factor, $\alpha=\frac{C_{0} V_{o c}}{x_{M}}$, which is defined by voltage $\left(V_{o c}\right)$ and displacement magnitude $\left(x_{M}\right)$ in open-circuit conditions.

In order to collect the output power provided by the harvester, a full-bridge rectifier with a smoothing capacitor, $C_{r}$, was used (Fig. $3 \mathrm{~b}$ ). The bridge was then connected to a resistive load, $R_{l}$, making a lumped circuit. For this system, the modified coupling coefficient is $k_{m}{ }^{2}=\frac{\alpha^{2}}{K C_{0}}$, which is the ratio between electrostatic energy stored in the system and the elastic energy, and the quality factor, $Q=\frac{\sqrt{K M}}{C}$. When the system is driven by a constant-magnitude force, in the case of continuous excitation of the harvester 
at resonance, the energy extraction circuit is attenuating the displacement of the beam. This effect is more evident for systems with high $Q$ or $k_{m}{ }^{2}$. Thus, the normalized power can be expressed as [20]:

$$
\bar{P}=8 k_{m}{ }^{2} \frac{r \Omega^{2}}{\left(r \Omega+\frac{\pi}{2}\right)^{2}}|\bar{x}|^{2},
$$

where the normalized frequency is $\Omega=\frac{\omega}{\omega_{0}}$, normalized load $-r=\omega_{0} C_{0} R_{l}$, and normalized displacement, $\bar{x}$. It is known [21] that the figure of merit, $k_{m}{ }^{2} Q$, can be used for the comparison of the harvester performance. If the harvester shows $k_{m}{ }^{2} Q>\pi$, the normalized power is fundamentally limited by the mechanical damping of the system, and therefore tends to reach the value of $Q$. In this scenario, we deal with a highly-coupled device showing two identical power peaks that correspond to the shortcircuit $\left(\omega_{0}\right)$ and open-circuit $\left(\omega_{0} \sqrt{1+k_{m}^{2}}\right)$ frequencies. Furthermore, it is possible to increase the bandwidth of the harvester by adjusting the resistive load to maximize the power output. The analytical model for standard rectification circuit was discussed in detail by Shu et al [22].

The transformer ratio, $\alpha$, was measured in open-circuit condition. From the impedance spectrum investigations, we obtained the lumped-model parameters, summarized in Table 1. The measured shortand open-circuit frequencies were $104.5 \mathrm{~Hz}$ and $105.9 \mathrm{~Hz}$, respectively. The experimentally identified quality factor was $\mathrm{Q}=396$ and the modified structural coupling ${k_{m}}^{2}=0.028$, leading to an estimated figure of merit of $k_{m}{ }^{2} Q=11$, which indicated that our studied system was highly-coupled [22]. These values are typical for single crystal materials [23], but they represent a significant improvement compared to our previous results [15] $\left(k_{m}{ }^{2} Q=0.3\right)$. Indeed, in this study we had considered $\mathrm{LiNbO}_{3}$ (YXlt) $/ 128^{\circ} / 90^{\circ}$, which effectively increased the transverse electromechanical coupling [13] compared to (YXlt) $/ 36^{\circ} / 90^{\circ}$ orientation. Therefore, the choice of the crystal orientation is of essential importance in terms of performances.

To estimate the harvester output power, the DC voltage was measured after a full bridge rectification circuit. The circuit was essentially composed by four $1 \mathrm{~N} 4148$ diodes and one smoothing capacitor, $C_{r}$ $=12 \mu \mathrm{F}$, followed by a variable resistive load, $R_{l}$. The rectified voltage, $V_{D C}$, was used to estimate the power output, $P=\frac{V_{D C}{ }^{2}}{R_{l}}$. In the case of highly coupled regime, we expect to have two power peaks for short- and open-circuit frequencies. A comparison between simulated (Eq. 2) and experimental power is given in Fig. 4a. The $V_{D C}$ was measured as a function of the frequency for each resistive load, in order to investigate the behavior at both short- and open-circuit conditions. In terms of harvested power, a projection of the theoretical surface along with the data points is plotted in the plane to illustrate the dependency on the resistive load and frequency. Two power peaks were identified: one relative to the 
short-circuit resonance $(50 \mathrm{k} \Omega$ ) and one at open-circuit $(3 \mathrm{M} \Omega)$. Nevertheless, four fast-switching diodes were used in the rectification circuit, resulting in power losses for the short-circuit resistive load, where the voltage level was close to $1 \mathrm{~V}$. Since diode losses were not considered in the model, the power at short-circuit resonance is lower compared to the simulation. Nevertheless, the optimal rectified power output for the short-circuit frequency was $\mathrm{P}_{\mathrm{sc}}=29 \mu \mathrm{W}$, while for open-circuit frequency was $\mathrm{P}_{\mathrm{oc}}=41.5$ $\mu \mathrm{W}$. Finally, considering the low acceleration level, we attain a considerably high normalized power density ( $\mathrm{NPD}=965 \mu \mathrm{W} / \mathrm{cm}^{2} / \mathrm{g}^{2}$ ), which is among the highest values reported in literature for a $\mathrm{Pb}$ and $\mathrm{Pb}$-free based energy harvester. Typically, other devices that are working in similar conditions can reach higher power levels but are implementing two piezoelectric layers in bimorph configuration. Even if $\mathrm{LiNbO}_{3}$ bimorphs with inversion layers were fabricated by using bulk crystal wafers [16], their impedance matching issues with the electronic interfaces and limited flexibility were limiting their application. For this reason, we propose a thick film implementation, which results in a highly coupled device with rectified power response. Many authors tend to report the instantaneous power for vibrational harvesters which could be misleading, while in this work the rectified power was measured, confirming that it is possible to implement $\mathrm{LiNbO}_{3}$ thick films transducers as vibrational energy harvester with standard electronic interface.

The normalized power densities of low frequency energy harvesters, reported in literature, are compared to the one of our studied vibrational $\mathrm{LiNbO}_{3}$ harvesters in Fig. $4 \mathrm{~b}$. The state of the art is a selection of works for both MEMS devices [24,25,26,27] exploiting materials that are deposited by means of microfabrication techniques, and meso-scale [28,29,30,31] devices exploiting commercially available ceramics or single crystals. Although they present different dimensions, their power is normalized by the active surface and input acceleration for a fair comparison. Finally, $\mathrm{Pb}$-free MEMS devices show NPD up to $495 \mu \mathrm{W} / \mathrm{cm}^{2} / \mathrm{g}^{2}$ for (MgZr)AlN/Si harvesters at high frequency (at $792 \mathrm{~Hz}$ ) [32] and 71 $\mu \mathrm{W} / \mathrm{cm}^{2} / \mathrm{g}^{2}$ for $\mathrm{LiNbO}_{3}$ (at $1140 \mathrm{~Hz}$ ) [15]. Therefore, devices with large tip mass can attain higher power densities compared to simple beams as in our previous work, but they tend also be more fragile at high acceleration levels. In the case of low frequency devices PMN-PT highly coupled devices [31] can attain $9083 \mu \mathrm{W} / \mathrm{cm}^{2} / \mathrm{g}^{2}$ at $28 \mathrm{~Hz}$, while PZT [6] and $\mathrm{LiNbO}_{3}$ harvesters can attain similar power densities in the order of $1039 \mu \mathrm{W} / \mathrm{cm}^{2} / \mathrm{g}^{2}$ and $965 \mu \mathrm{W} / \mathrm{cm}^{2} / \mathrm{g}^{2}$ respectively. However, it is important to note that at low frequency, (YXlt) $/ 128^{\circ} / 90^{\circ} \mathrm{LiNbO}_{3} / \mathrm{Si}$ unimorph attains the highest performance among other leadfree materials. Even if relaxor ferroelectrics are showing higher normalized power density compared to our prototype, their expensive price and toxicity prevent them to be widely used in energy harvesting applications. Eventually, the performance of vibrational energy harvesters based on $\mathrm{LiNbO}_{3}$ thick films can be further improved by implementing bimorphs on metal substrates [6].

In conclusion, a beam with tip mass, based on $\mathrm{LiNbO}_{3}$ single-crystal film bonded on silicon, was investigated for the vibrational energy harvesting at low frequencies. The dynamic behavior was simulated by finite element method, whereas the single degree of freedom lumped-model was used to 
simulate the power level of the harvester. Our device presented a short- and open-circuit resonance frequencies of respectively 104.5 and $105.9 \mathrm{~Hz}$. The device electromechanical coupling was $\mathrm{k}_{\mathrm{m}}{ }^{2}=2.8 \%$, and the quality factor was $\mathrm{Q}=396$. The figure of merit $\left(k_{m}{ }^{2} Q=11\right)$ was indicating highly-coupled device behavior and the measured power density was $965 \mu \mathrm{W} / \mathrm{cm}^{2} / \mathrm{g}^{2}$, which is among the highest reported values compared to both $\mathrm{Pb}$ - and $\mathrm{Pb}$-free vibrational harvesting devices. For future investigations, the fragility of the silicon-based beams can be overcome by the integration of $\mathrm{LiNbO}_{3}$ thick films on more reliable or flexible substrates, such as metal foils.

Acknowledgments

This research was funded by European MSCN-ITN-ENHANCE program grant number 722496, French RENATECH network, EUR EIPHI program grant number ANR-17-EURE-0002.

Table 1: Lumped model parameters, identified experimentally for (YXlt) $/ 128^{\circ} / 90^{\circ} \quad \mathrm{LiNbO}_{3} / \mathrm{Si}$ harvester.

\begin{tabular}{cccc}
\hline $\mathbf{M}(\mathbf{g})$ & $\mathbf{C}(\mathbf{m N . s} / \mathbf{m})$ & $\mathbf{K}(\mathbf{N} / \mathbf{m})$ & $\boldsymbol{\alpha}(\mathbf{m N} / \mathbf{V})$ \\
\hline 0.416 & 0.691 & 179.54 & 0.17 \\
\hline
\end{tabular}



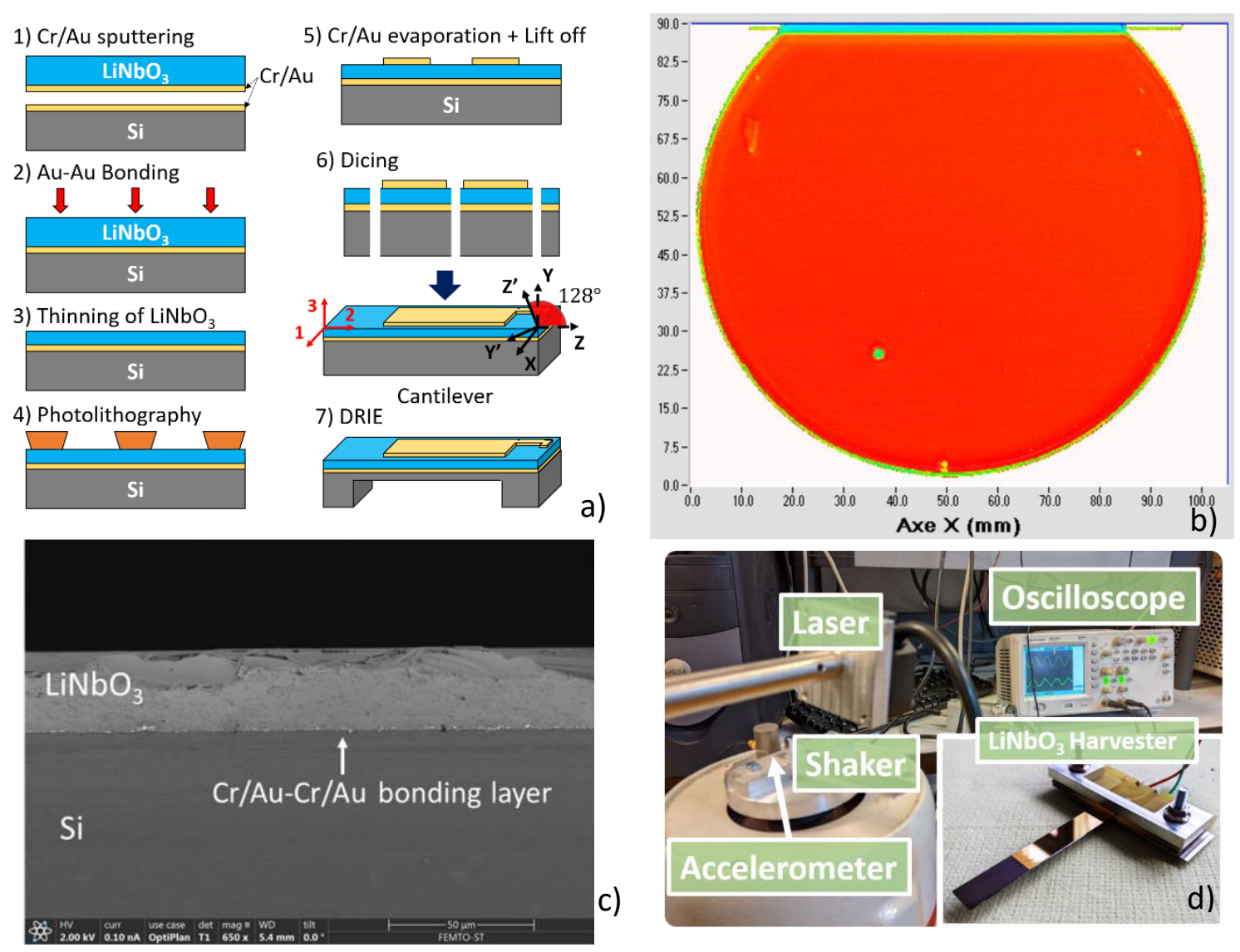

Figure 1: a) Microfabrication flowchart for (YXlt)/ $128^{\circ} / 90^{\circ} \mathrm{LiNbO}_{3}$ harvester: 1) $\mathrm{Cr} / \mathrm{Au}$ sputtering on polished $\mathrm{LiNbO}_{3}$ and $\mathrm{Si}$ wafers; 2) EVG bonding of $\mathrm{Cr} / \mathrm{Au}$ interface layers; 3) lapping and polishing of $\mathrm{LiNbO}_{3}$ wafer; 4) UV photolithography patterning and development; 5) deposition and lift-off of $\mathrm{Cr} / \mathrm{Au}$ top electrodes; 6) mechanical dicing of cantilever structures with explicit rotation around $\mathrm{X}$ (in red) of the axes $\mathrm{Y}$ and Z; 7) deep reactive ion etching of Si substrate. Bonding interface quality between $\mathrm{Si}$ and (YXIt) $/ 128^{\circ} / 90^{\circ} \mathrm{LiNbO}_{3}$ wafers: b) ultrasonic imaging of bonded wafers surface, c) SEM image of cross section of (YXlt) $/ 128^{\circ} / 90^{\circ} \quad \mathrm{LiNbO}_{3} / \mathrm{Si}$ heterostructure. d) Characterization setup for vibrational energy harvesters, (inset) (YXlt) $/ 128^{\circ} / 90^{\circ}$ $\mathrm{LiNbO}_{3} / \mathrm{Si}$ energy harvester clamped and wire-bonded on PCB. 

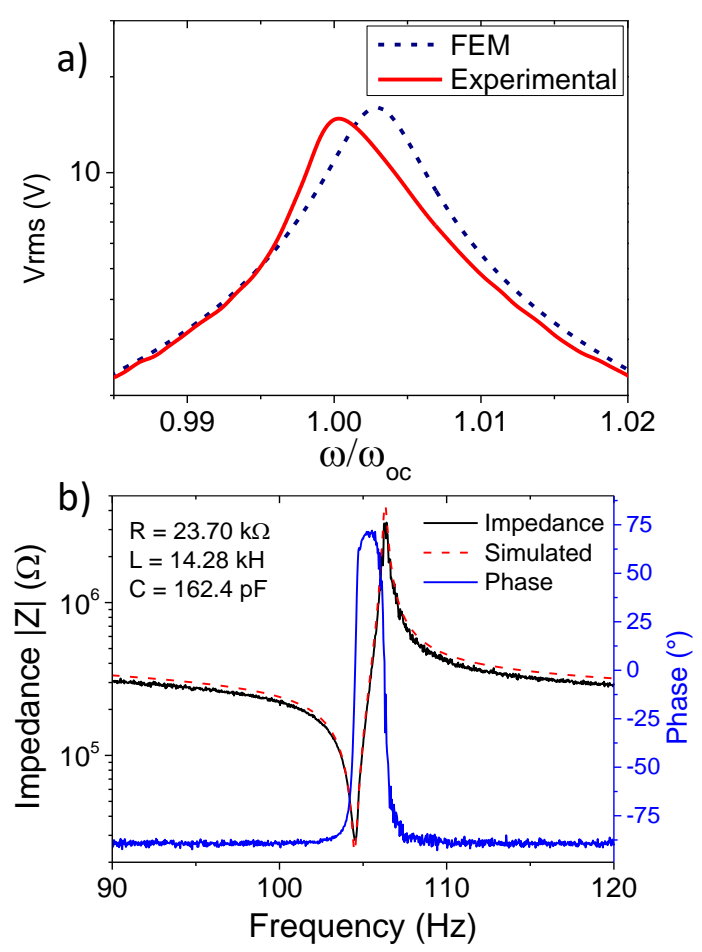

Figure 2: Frequency dependence of a) experimental and FEM voltage response (RMS) and b) impedance and phase response along with BVD simulation for (YXIt) $/ 128^{\circ} / 90^{\circ} \mathrm{LiNbO}_{3} / \mathrm{Si}$ harvester

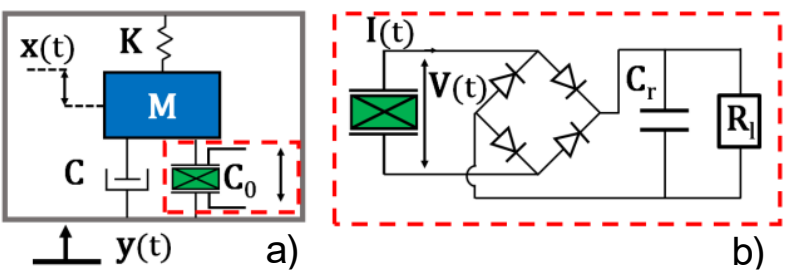

Figure 3: Inertial energy harvester schematics: a) equivalent electro-mechanical lumped model for inertial energy harvester, b) full-bridge rectification circuit with resistive load. 
a)

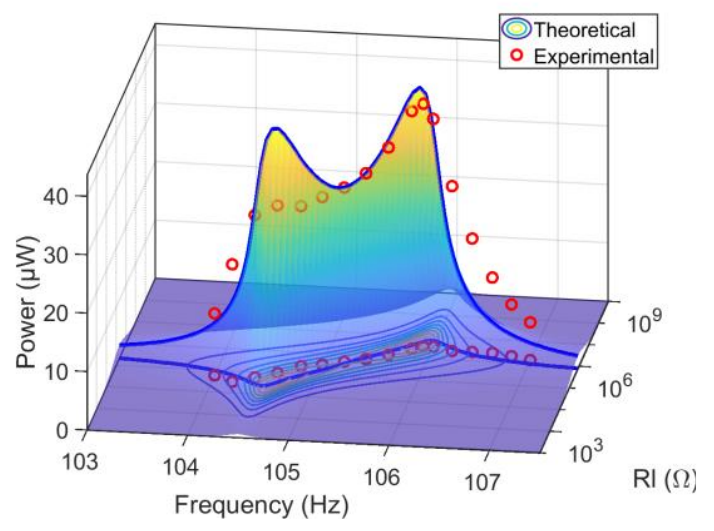

b)

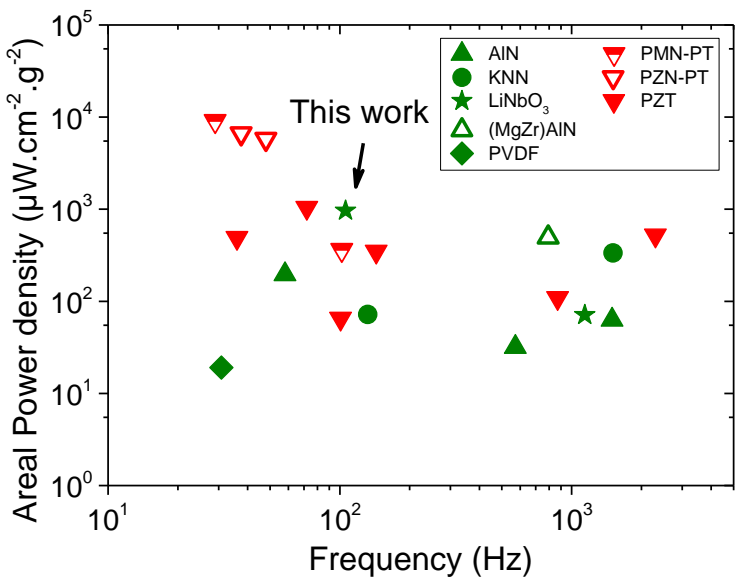

Figure 4: a) Comparison of theoretical and experimental power output of (YXlt) $/ 128^{\circ} / 90^{\circ}$ $\mathrm{LiNbO}_{3} / \mathrm{Si}$ harvester in terms of frequency and resistive load. The transparent surface represents the simulated power using the proposed model, while the experimental maxima are depicted. b) Comparison of normalized power density for $\mathrm{Pb}$-based (red) and $\mathrm{Pb}$-free (green) MEMS and mesoscale devices, reported in literature and studied in this work.

\section{DATA AVAILABILITY}

The data that support the findings of this study are available from the corresponding author upon reasonable request.

\section{References}

[1] Z. Yang, S. Zhou, J. Zu, and D. J. Inman, "High-Performance Piezoelectric Energy Harvesters and Their Applications," Joule 2(4), 642-697 (2018).

[2] D. Evans, The Internet of Things. How the Next Evolution of the Internet is Changing Everything (CISCO White Paper, 2011).

[3] H. A. Sodano, D. J. Inman, and G. Park, "Comparison of Piezoelectric Energy Harvesting Devices for Recharging Batteries,” J. Intell. Mater. Syst. Struct, 16(10), 799-807 (2005).

[4] G. Tang, B. Yang, C. Hou, G. Li, J. Liu, X. Chen, and C. Yang, "A piezoelectric micro generator worked at low frequency and high acceleration based on PZT and phosphor bronze bonding," Sci. Rep. 6, 38798 (2016).

[5] C. L. Kuo, S. C. Lin, and W. J. Wu, "Fabrication and performance evaluation of a metal-based bimorph piezoelectric MEMS generator for vibration energy harvesting," Smart Mater. Struct. 25(10), 1-10 (2016).

[6] H. G. Yeo, and S. Trolier-McKinstry, "Effect of piezoelectric layer thickness and poling conditions on the performance of cantilever piezoelectric energy harvesters on Ni foils" Sens. Actuators, A, 273, 90-97 (2018). 
[7] Z. Yang, and J. Zu, "Comparison of PZN-PT, PMN-PT single crystals and PZT ceramic for vibration energy harvesting," Energy Convers. Manag. 122, 321-329 (2016).

[8] R. Andosca, T. G. McDonald, V. Genova, S. Rosenberg, J. Keating, C. Benedixen, and J. Wu, "Experimental and theoretical studies on MEMS piezoelectric vibrational energy harvesters with mass loading," Sens. Actuators, A, 178, 76-87 (2012).

[9] R. Sriramdas, S. Chiplunkar, R. M. Cuduvally, and R. Pratap, "Performance enhancement of piezoelectric energy harvesters using multilayer and multistep beam configurations," IEEE Sens. J., 15(6), 3338-3348 (2015).

[10] T. Shiraishi, N. Kaneko, M. Kurosawa, H. Uchida, Y. Suzuki, T. Kobayashi and H. Funakubo, "Vibrationenergy-harvesting properties of hydrothermally synthesized $(\mathrm{K}, \mathrm{Na}) \mathrm{NbO} 3$ films deposited on flexible metal foil substrates,” Jpn. J. Appl. Phys. 54(10) (2015).

[11] G. Clementi, S. Margueron, M. A. Suarez, T. Baron, B. Dulmet, and A. Bartasyte, "Piezoelectric and Pyroelectric Energy Harvesting from Lithium Niobate Films,” J. Phys. Conf. Ser., 1407(1) (2019).

[12] G. Kovacs, M. Anhorn, H. E. Engan, G. Visintini, and C. C. W Ruppel, "Improved material constants for LiNbO3 and LiTaO3," Proc. IEEE Ultrason. Symp., 1, 435-438 (1990).

[13] K. Nakamura, H. Ando, and H. Shimizu, "Bending vibrator consisting of a LiNbO3 plate with a ferroelectric inversion layer,” Jpn. J. Appl. Phys. 26, 198-200 (1987).

[14] IEEE Standard on Piezoelectricity, ANSI/IEEE Std 176-1987 (1988).

[15] G. Clementi, G. Lombardi, S. Margueron, M. A. Suarez, E. Lebrasseur, S. Ballandras, J. Imbaud, F. Lardet Vieudrin, L. Gauthier Manuel, B. Dulmet, M. Lallart, and A. Bartasyte, "LiNbO3 films - A low-cost alternative lead-free piezoelectric material for vibrational energy harvesters," Mech Syst Signal Process, 149, 107171 (2021).

[16] J. V. Vidal, A. V. Turutin, I. V. Kubasov, A. M. Kislyuk, M. D. Malinkovich, Y. N. Parkhomenko, N. A. Sobolev, A. L. Kholkin, "Low-Frequency Vibration Energy Harvesting with Bidomain LiNbO3 Single Crystals," IEEE Trans Ultrason Ferroelectr Freq Control 66(9), 1480-1487 (2019).

[17] T. Baron, E. Lebrasseur, F. Bassignot, G. Martin, V. Pétrini, S. Ballandras, Modeling and Measurement Methods for Acoustic Waves and for Acoustic Microdevices, 297 (InTechOpen 2013).

[18] A. Bartasyte, S. Margueron, T. Baron, S. Oliveri, and P. Boulet, "Toward High-Quality Epitaxial LiNbO3 and LiTaO3 Thin Films for Acoustic and Optical Applications," Adv. Mater. Interfaces, 4(8), 1-36 (2017).

[19] Y. C. Wang, S. A. Chen, Y. C. Shu, S. C. Lin, C. T. Chen, and W. J. Wu, "Nonlinear analysis of micro piezoelectric energy harvesters," SPIE Conf. Series 10164, 1016418 (2017).

[20] A. Badel, and E. Lefeuvre, Nonlinear Conditioning Circuits for Piezoelectric Energy Harvesters. (Springer 2016).

[21] D. Guyomar, A. Badel, E. Lefeuvre, and C. Richard, "Toward energy harvesting using active materials and conversion improvement by nonlinear processing" IEEE Trans Ultrason Ferroelectr Freq Control 52(4), 584$594(2005)$.

[22] Y. C. Shu, and I. C. Lien, "Analysis of power output for piezoelectric energy harvesting systems," Smart Mater. Struct. 15(6), 1499-1512 (2006).

[23] E. Lefeuvre, A. Badel, A. Benayad, L. Lebrun, C. Richard, and D. Guyomar, "A comparison between several approaches of piezoelectric energy harvesting," J. Phys. IV France, 128, 177-186 (2005).

[24] D. Isarakorn, D. Briand, P. Janphuang, A. Sambri, S. Gariglio, J.M. Triscoe, F. Guy, J.W. Reiner, C.H. Ahn, N.F. de Rooij, "The realization and performance of vibration energy harvesting MEMS devices based on an epitaxial piezoelectric thin film," Smart Mater. Struct. 20, 025015 (2011).

[25] M. Marzencki, Y. Ammar, S. Basrour, "Integrated power harvesting system including a MEMS generator and a power management circuit," Sens. Actuat. A Phys. 145-146, 363-370 (2008).

[26] A.B. Alamin Dow, A. Bittner, U. Schmid, N.P. Kherani, "Design, fabrication and testing of a piezoelectric energy microgenerator," Microsyst Technol 20, 1035-1040 (2014).

[27] P. Muralt, M. Marzencki, B. Belgacem, F. Calame, S. Basrour, "Vibration energy harvesting with PZT micro device," Proc. Chem. 1, 1191 (2009).

[28] L. Dhakar, H. Liu, F. E. Tay, and C. Lee, "A new energy harvester design for high power output at low frequencies," Sens. Actuators, A, 199, 344-352 (2013).

[29] C. Xu, B. Ren, W. Di, Z. Liang, J. Jiao, L. Li, L. Li, X. Zhao, H. Luo, and D. Wang, "Cantilever driving low frequency piezoelectric energy harvester using single crystal material $0.71 \mathrm{~Pb}(\mathrm{Mg} 1 / 3 \mathrm{Nb} 2 / 3) \mathrm{O} 3-0.29 \mathrm{PbTiO}$," Appl. Phys. Lett. 101(3), 2010-2014 (2012).

[30] S. S. Won, J. Lee, V. Venugopal, D. J. Kim, J. Lee, I.W. Kim, A. I. Kingon, and S. H. Kim, "Lead-free Mndoped (K0.5,Na0.5)NbO3 piezoelectric thin films for MEMS-based vibrational energy harvester applications," Appl. Phys. Lett. 108(23), 0-5 (2016).

[31] D. Gibus, P. Gasnier, A. Morel, F. Formosa, L. Charleux, S. Boisseau, G. Pillonnet, C. A. Berlitz, A. Quelen, and A. Badel, "Strongly coupled piezoelectric cantilevers for broadband vibration energy harvesting," Appl. Energy, 277, 115518 (2020). 
[32] L. Van Minh, M. Hara, T. Yokoyama, T. Nishihara, M. Ueda, and H. Kuwano, "Highly piezoelectric MgZr co-doped aluminum nitride-based vibrational energy harvesters," IEEE Trans Ultrason Ferroelectr Freq Control 62(11), 2005-2008 (2015). 